\title{
Fostering autonomous learning in a science classroom among under-credited over age students: An inquiry action research
}

Gitgano, Rubilyn L. $\bowtie$

NYC Department of Education, USA (rubgit@gmail.com)

Cuyacot, Eljim P.

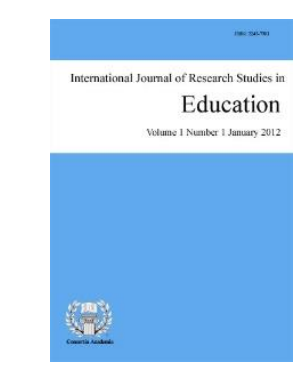

NYC Department of Education, USA (ecuyacot@gmail.com)

ISSN: 2243-7703

Cuyacot, Marilo T.

OPEN ACCESS

(mcuyacot01@gmail.com)

Sol Cruz, Florlilinda L.

NYC Department of Education, USA (enjefus@yahoo.com)

\section{Abstract}

This action research explores a classroom strategy and intervention to foster students' autonomy and independence in learning through the use of instructional and tracking tools developed by the teachers in response to the problem of practice commonly encountered by educators in under credited overaged transfer high schools. This inquiry action research involves three phases. The first phase involves knowing the students' needs, identifying goals, and designing the necessary resources and tools, the second phase involves using the resources and applying strategies, and the third phase involves evaluating and analyzing the outcomes to determine future action. This team of researchers believed that educators can create a classroom environment that facilitates and supports independent, self-directed, and autonomous learners by putting structures in place to guide students in their coursework.

Keywords: action research, autonomous learning, inquiry, under-credited overage, classroom strategy, intervention, self-regulation, classroom environment 


\section{Fostering autonomous learning in a science classroom among under-credited over age students: An inquiry action research}

\section{Introduction}

The New York City Department of Education, under then No Child Left Behind is mandated to provide students who are over age and are lagging behind in credits the opportunity to complete and earn a high school diploma. To attain this goal of re-engaging overage, under-credited students, a group of schools called transfer high schools are created to cater the specific needs of these groups. Transfer high schools are small, full-time high schools designed to help re-engage students who are falling behind in their credits to get back on track. The curriculum at transfer high schools is rigorous, and students earn a high school diploma. A transfer high school is a non-traditional environment for students 16 years of age or older who have attended high school for at least one year but may have fallen behind in credits towards graduation. Such schools are not normally organized according to traditional 9-12 grade structures. Rather, students learn at their own pace through varied learning delivery or coursework and with the help of a personal advisor to ensure they are getting the credits they need to graduate. In addition, students are usually able to gain access to paid internships and career planning services.

As mentioned previously, transfer high schools are created to provide opportunity for students who might have experienced "academic challenges" thus lack of motivation and negative attitudes displayed in the classrooms are some of the most common observations teachers see inside their classrooms. This statement is confirmed by some of the following observations: students arrive at class unprepared, put their heads down, and repeatedly seek teachers' assistance to complete academic tasks. These are not only physically draining to the teachers, but also detrimental to the academic growth of the students. In addition, this brought big pedagogical challenges for teachers like us who strongly believed in the constructivist theory of teaching by doing. The belief that students learn best when they are exposed to activities that allow them to learn from their mistakes; construct theories out of experiment and be able to construct meaning out of their own experiences. It is the strong contention of this team of researchers that when students are actively involved in exploring and understanding the concept and with teachers being the facilitators of learning they learn better and the concept becomes more meaningful and impactful. In light of the initial observations and patterns of student behavior in a transfer high school setting, we thought some strategies might be helpful to address the problem of having unmotivated, teacher dependent learners. Hence, this case study was developed. The case study employed the use of the Inquiry Learning Cycle. Students' academic disposition and behavior has been thoroughly monitored as well as the students' interest and learning styles are determined at the beginning of every trimester. Teachers' knowledge of each student's unique skills is essential to tailor instruction effectively towards their learning needs, as York (2014) points out. Educators can create instruction that appeals to students' interests, academic dispositions, and learning styles in the hopes that they will motivate them to take an active role in their education. Thus the Implementation phase of this action research initiates around this process.

Implementation phase of this inquiry action research cycle also involves the creation of the instructional monitoring tools such as checklists, rubrics, and written directives for each student task. The assumption here is that the use of qualitative data from classroom observations, the student interest learning style survey along with the tracking assessment tools will resolve the challenges of having unmotivated, teacher dependent learners that most teachers in transfer high schools have been struggling to address. This team of researchers believed that putting structures in place to guide students in their coursework is important to become independent, self-directed, and autonomous learners.

\subsection{Statement of the problem}

This research examined some strategies to foster students' motivation and involvement in their learning with 
Fostering autonomous learning in a science classroom among under-credited over age students

the hope that through these strategies students would develop to be independent and self-directed learners. Specifically, it aimed to answer the following questions:

$>$ How might we effectively use systems in the classroom to develop autonomous learners?

$>\quad$ How might we push students to work independently with minimal assistance from the teacher?

\section{Literature review}

There are several meanings associated with autonomous learning. Even though autonomy is heralded as an essential aim of education, it means different things to different people. As used in this case study, learner autonomy refers to learner independence and self-directed learning - i.e., the ability to complete assigned tasks with minimal assistance from the teacher. According to Holec (2001, p. 48), one of the first proponents of autonomy for language teachers, defines autonomy as the ability to adapt one's own learning. Dickinson (1987, cited in Gardner \& Miller, 1996, p. 6) defines autonomy as "when the learner is responsible for making and implementing all the decisions regarding his or her learning." Moreover, Omaggio (1978) states there seem to be seven main attributes characterizing autonomous learners:

$>\quad$ Students who learn autonomously are aware of their learning styles and strategies;

$>\quad$ Learning autonomously involves an active approach to the task at hand;

$>$ A self-directed learner is willing to take risks, communicate in the target language as much as possible;

$>\quad$ Autonomous learners are good guessers;

$>$ Additionally, autonomous learners emphasize accuracy and relevance as well as form and content.

$>\quad$ The autonomous learner develops the target language into his or her own reference system and is open to revising and rejecting logical hypotheses and rules that do not fit. These learners are tolerant, open, and communicative towards the target language (Thansoulas, 2000).

A critical look at the teacher's role - Little (1991) noted that learner autonomy and teacher autonomy are interdependent, and that teachers who wish to promote greater student autonomy must "start with themselves", reflecting on their own beliefs, practices, experiences, and expectations for the teaching/learning situation. The teacher's control over what is being transmitted does not become redundant as a result of learner autonomy (Thanasoulas, 2000). As a teacher, you must maintain a learning environment so that the students feel empowered to make decisions about their learning.

Autonomy and Learning Strategy - Zimmerman (1998) emphasizes that strategic learners are those who are able to control the locus of control throughout the learning process. They develop their self-management skills by experiencing positive events in their lives, by interactions with others, through verbal persuasion, and by experiencing a positive physiological state (Ustunlouglu, 2009), and eventually become self-regulated learners.

How to achieve autonomy? For learners to achieve autonomy, they have to follow certain paths, which is tantamount to claiming there will be a teacher who will show them the way. Therefore, autonomous learning is not "teacher-less learning" (Thanasoulas, 2000). The role of teachers in launching learners into self-access and providing them with regular support is critical.

\section{Methodology}

\subsection{PRE-Implementation}

During the onset of this study, Math and Science Department teachers regularly meet once a week to discuss 
some of the instructional challenges that the department encountered in the first few weeks of the trimester. Commonalities and patterns of the teachers' instructional concerns and challenges were categorized into themes and an overall department problem of practice was determined. Math and science Department team leaders then shared the issues with the Instructional Leadership Team (ILT) and the school administrators during consultation meetings to brainstorm on the possible ways to address the problem of practice identified in the Math and Science Department. After consultation with the Instructional Lead Team and administrators, the team suggested that conducting an inquiry through action research was deemed to be a good way to begin exploring the solution to the problem.

As part of the suggested action research, Science and Math Content Leaders facilitated and finalized the protocol and theme for the inquiry in each department. The inquiry action research design which included the problem of practice and its protocol were submitted to the administrators for approval. The two science teachers were notified and the class respondents were identified.

\subsection{During implementation}

In this study, the researcher addressed the important role that teachers play in the development of self-directed learners. Thus the first step in the implementation stage was training the teachers about the inquiry process and the cycle of work. The second step of the implementation process was to determine the learning styles and interests of students. Based on the data gathered from initial classroom noticing and the teachers' challenges shared during regular weekly meetings, the team created structures and instructional tools to motivate students to get involved with their learning and train students to work independently. Instructional tools such as rubrics, checklists and selfassessment scales allow students to chart their progress. Providing students with these instructional tools and tracking guidelines is believed to foster more independence and autonomy, as students tend to self-regulate their learning thereby requiring less assistance from their teachers.

Use of student learning style and interest survey - A student survey could provide insight into students' learning styles and interests. This tool was used by teachers to gather information about students' learning preferences and interests. It could be used to check in on students as well as plan lessons, classroom activities, and homework assignments. Study participants' learning styles and interests were matched with the characteristics reflected in the diagram below.

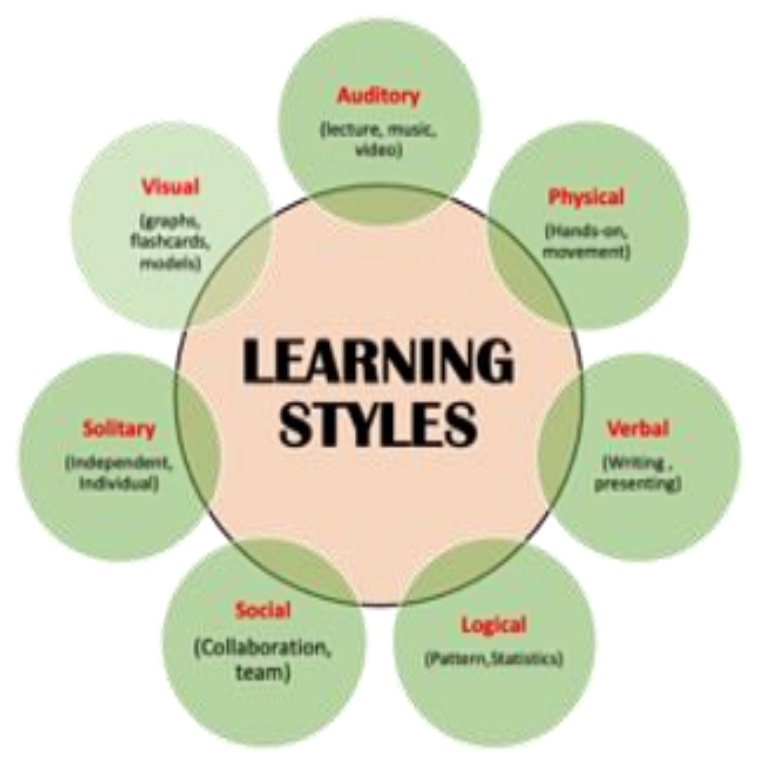

Figure 1. Learning style and interest

Use of instructional guide and tracking tools such as rubrics, checklists and written directives - As part of 
Fostering autonomous learning in a science classroom among under-credited over age students

the performance task and student outcome assessment, the team developed written directives, checklists and rubrics. For a week, the guides and tools are modeled in the classroom, and then the model is gradually removed until students can work independently. Below is an example of the rubric used during this study. Students used this as a self-assessment rubric.

\section{SCIENCE RUBRIC FOR SCHOOLWIDE FOCUS}

\begin{tabular}{|c|c|c|c|c|}
\hline Category & $\begin{array}{c}\text { Exceed } \\
\text { Standard (4) }\end{array}$ & $\begin{array}{c}\text { Met Standard } \\
\text { (3) }\end{array}$ & $\begin{array}{l}\text { Approaching } \\
\text { Standard (2) }\end{array}$ & $\begin{array}{l}\text { Does not met } \\
\text { Standard (1) }\end{array}$ \\
\hline $\begin{array}{l}\text { Identified key } \\
\text { ideas/elements and } \\
\text { important details }\end{array}$ & $\begin{array}{l}\text { Identified all key } \\
\text { ideas/elements and } \\
\text { important details }\end{array}$ & $\begin{array}{l}\text { Identified major key } \\
\text { ideas/elements and } \\
\text { important details }\end{array}$ & $\begin{array}{l}\text { Identified at least half of } \\
\text { the key ideas/elements } \\
\text { and details }\end{array}$ & $\begin{array}{l}\text { Identified very limited key } \\
\text { ideas/elements and details }\end{array}$ \\
\hline $\begin{array}{l}\text { Encircled /underline } \\
\text { unfamiliar words and } \\
\text { attempted to explain } \\
\text { through context }\end{array}$ & $\begin{array}{l}\text { Encircled/underline all } \\
\text { unfamiliar words and } \\
\text { attempted to explain it } \\
\text { contextually }\end{array}$ & $\begin{array}{l}\text { Encircled/underline most of } \\
\text { the unfamiliar words and } \\
\text { attempted to explain most } \\
\text { of it contextually }\end{array}$ & $\begin{array}{l}\text { Encircled/underline at } \\
\text { least half of the } \\
\text { unfamiliar words and } \\
\text { attempted to explain } \\
\text { some contextually }\end{array}$ & $\begin{array}{l}\text { Encircled/underline very } \\
\text { limited unfamiliar words and } \\
\text { have not attempted to } \\
\text { explain it contextually }\end{array}$ \\
\hline $\begin{array}{l}\text { Make connections } \\
\text { and raise thoughtful } \\
\text { questions to } \\
\text { information and notes }\end{array}$ & $\begin{array}{l}\text { Make } 3 \text { or more } \\
\text { connections/thoughtful } \\
\text { questions to information } \\
\text { and notes }\end{array}$ & $\begin{array}{l}\text { Make at least } 2 \\
\text { connections/thoughtful } \\
\text { questions to information } \\
\text { and notes }\end{array}$ & $\begin{array}{l}\text { Make at least } 1 \\
\text { connections /thoughtful } \\
\text { questions to information } \\
\text { and notes }\end{array}$ & $\begin{array}{l}\text { Failed to make any } \\
\text { connections/thoughtful } \\
\text { questions to information } \\
\text { and notes }\end{array}$ \\
\hline $\begin{array}{l}\text { Draw and analyze } \\
\text { evidence }\end{array}$ & $\begin{array}{l}\text { Provide and draw } \\
\text { evidence supported with } \\
\text { insightful } \\
\text { explanation/analysis of } \\
\text { evidence }\end{array}$ & $\begin{array}{l}\text { Provide and draw evidence } \\
\text { supported with clear } \\
\text { explanation/analysis of } \\
\text { evidence }\end{array}$ & $\begin{array}{l}\text { Provide and draw } \\
\text { evidence supported with } \\
\text { some explanation/ } \\
\text { analysis of evidence }\end{array}$ & $\begin{array}{l}\text { Provide no or incorrect } \\
\text { explanation/analysis }\end{array}$ \\
\hline $\begin{array}{l}\text { Use of content } \\
\text { specific vocabulary }\end{array}$ & $\begin{array}{l}\text { Uses more than } \\
\text { enough/appropriate } \\
\text { content specific } \\
\text { vocabulary in the } \\
\text { explanation }\end{array}$ & $\begin{array}{l}\text { Uses enough/appropriate } \\
\text { content specific vocabulary } \\
\text { in the explanation }\end{array}$ & $\begin{array}{l}\text { Uses limited/vague } \\
\text { content specific } \\
\text { vocabulary in the } \\
\text { explanation }\end{array}$ & $\begin{array}{l}\text { Attempted to use very } \\
\text { little, unrelated or } \\
\text { incarrect content specific } \\
\text { vocabulary in the } \\
\text { explanation }\end{array}$ \\
\hline
\end{tabular}

Figure 2. Use of tracking tools such as Rubric

On each student's desk is a laminated scale from 4-0 with 0 being the lowest and 4 being the highest. On a regular basis, students were encouraged to rate their level of completion and/or understanding using the selfassessment or rating scale. An example of this assessment criteria is shown below.

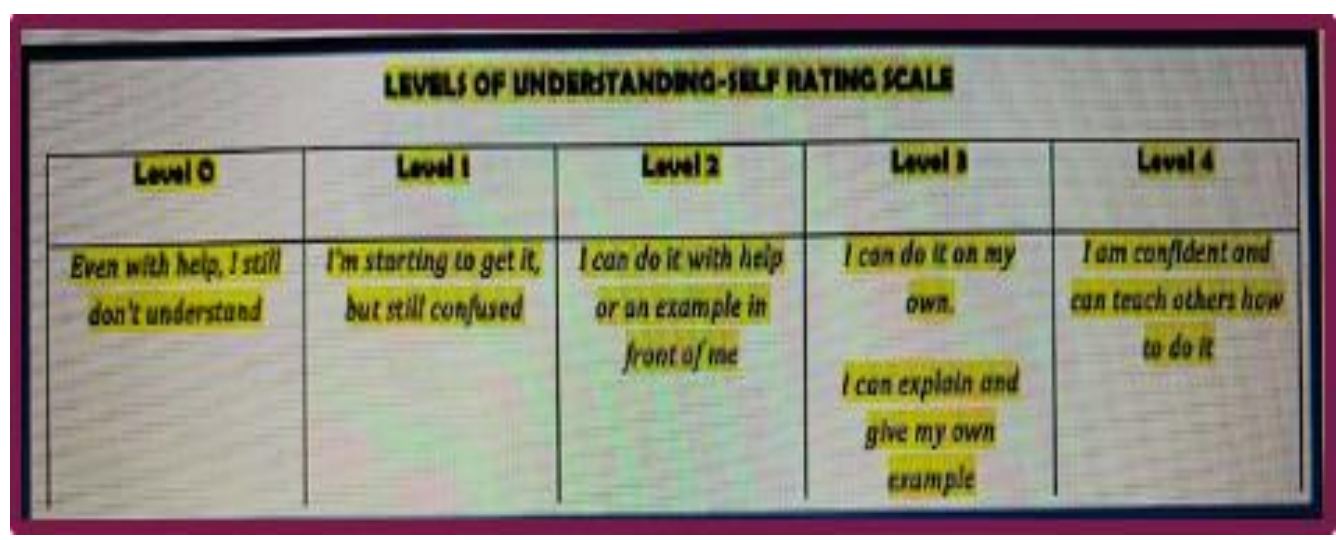

Figure 3. Self-Assessment Rating Scale

This self-assessment rating scale was used by students on a regular basis to assess their progress on an assignment. The next day's lesson will be based on the summary of the class' overall self-assessment. The outcome of the self-assessment rating determines whether to reteach or move forward with the next instructional goal.

\section{Results and discussion}

Students were given a learning style and interest survey during the first week of every trimester. The Google 
Forms was used so that the data can be collected easily. On the basis of students' responses, results were tabulated and patterns of learning style and interest are determined. This figure shows the results of the learning style and interest survey for Trimester 1 of the school year 2021 to 2022.

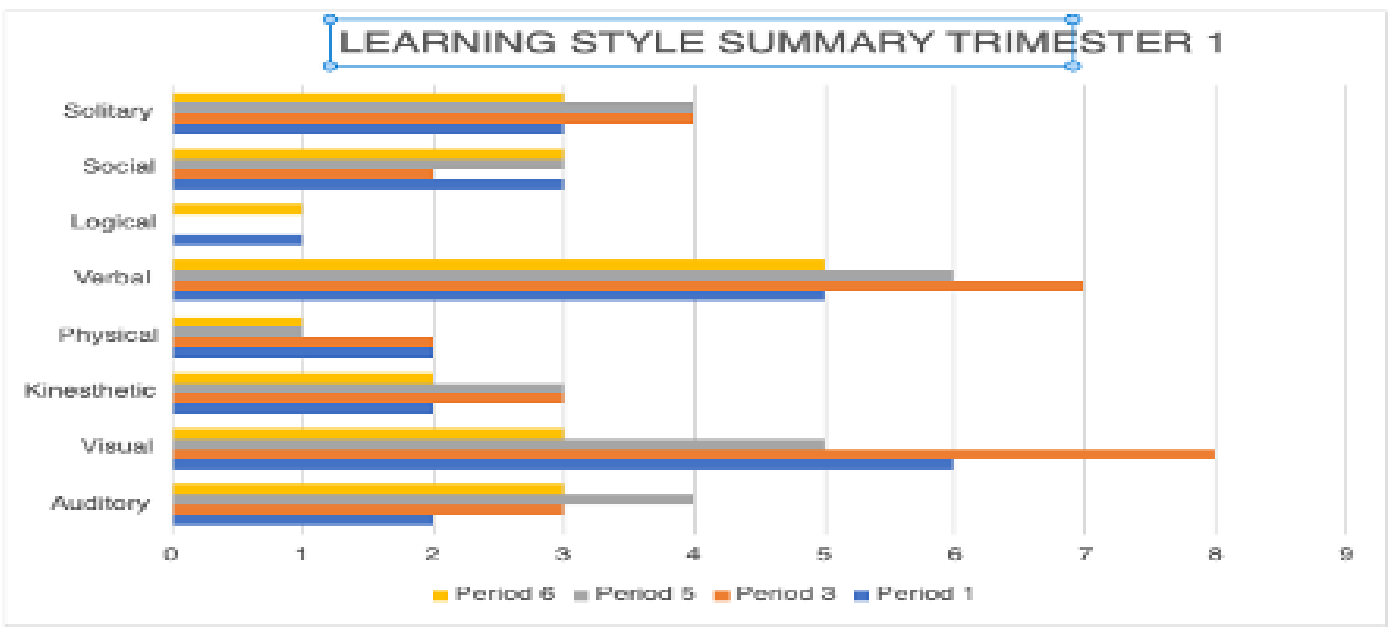

Figure 4. Learning Style and Interest Survey Result

According to this graph, most students in periods 1 through 6 demonstrate three different types of learning styles. Some are visually driven, others are verbal-driven, and some are individualistic learners. Although visual and verbal learners are able to work effectively and efficiently in groups, other students prefer to work independently. It was found that determining students' learning styles and interests were both crucial in planning relevant lessons and activities for students that were geared towards their interest.

Furthermore, a sample of the written instructions provided to students on annotation task is modeled below. Students were initially asked to annotate text for better comprehension. The annotation assignment was explained to students but the teachers noticed two concerning observations; the entire texts were highlighted and student teams repeatedly called for teacher guidance on what to do next. Thus, teachers thought a clear step by step procedure may be helpful.

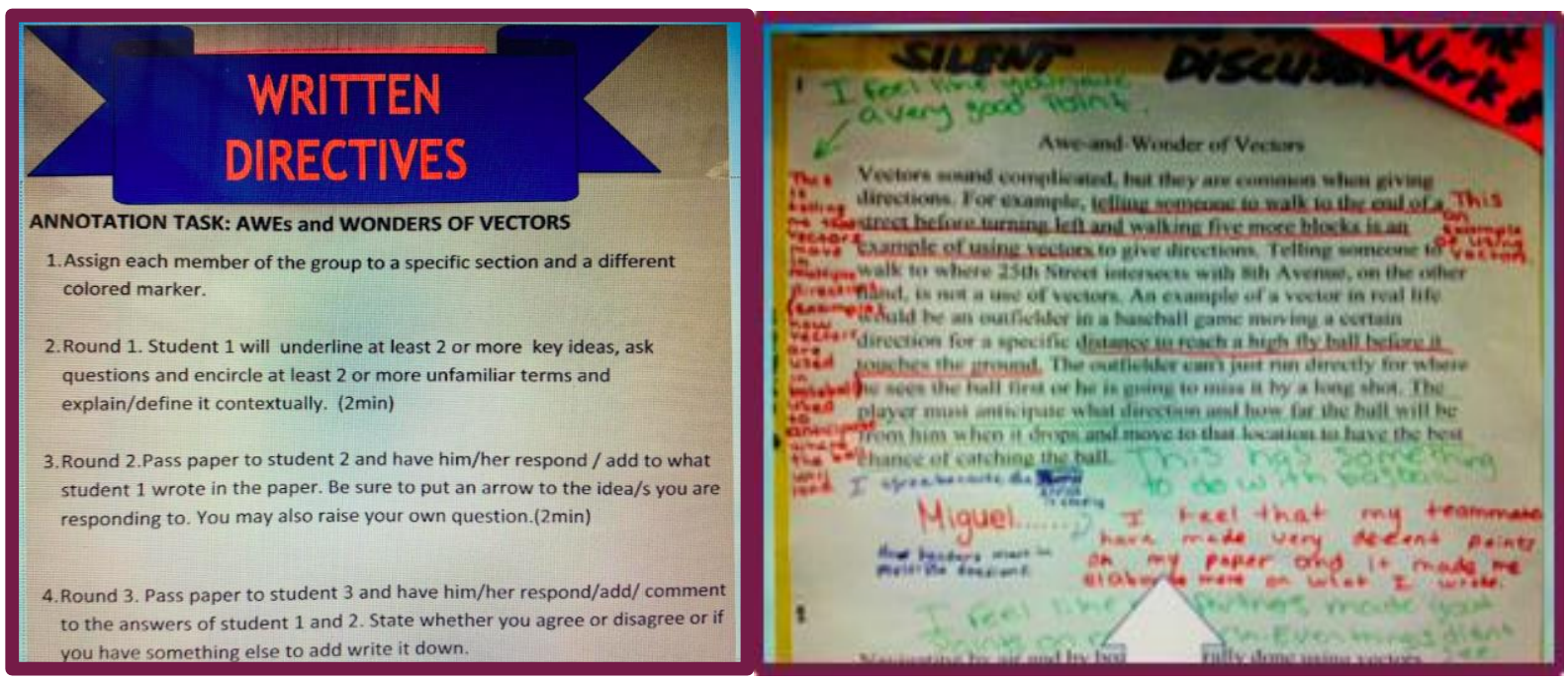

Figure 5. Sample Annotated Work with Instructions

Result of our initial implementation on the use of tracking tools also showed that when students received written directives, they have a more profound understanding of the text or task assigned, and their output meets teachers' expectations. There is a significant improvement in the students' output when given written instructions. 


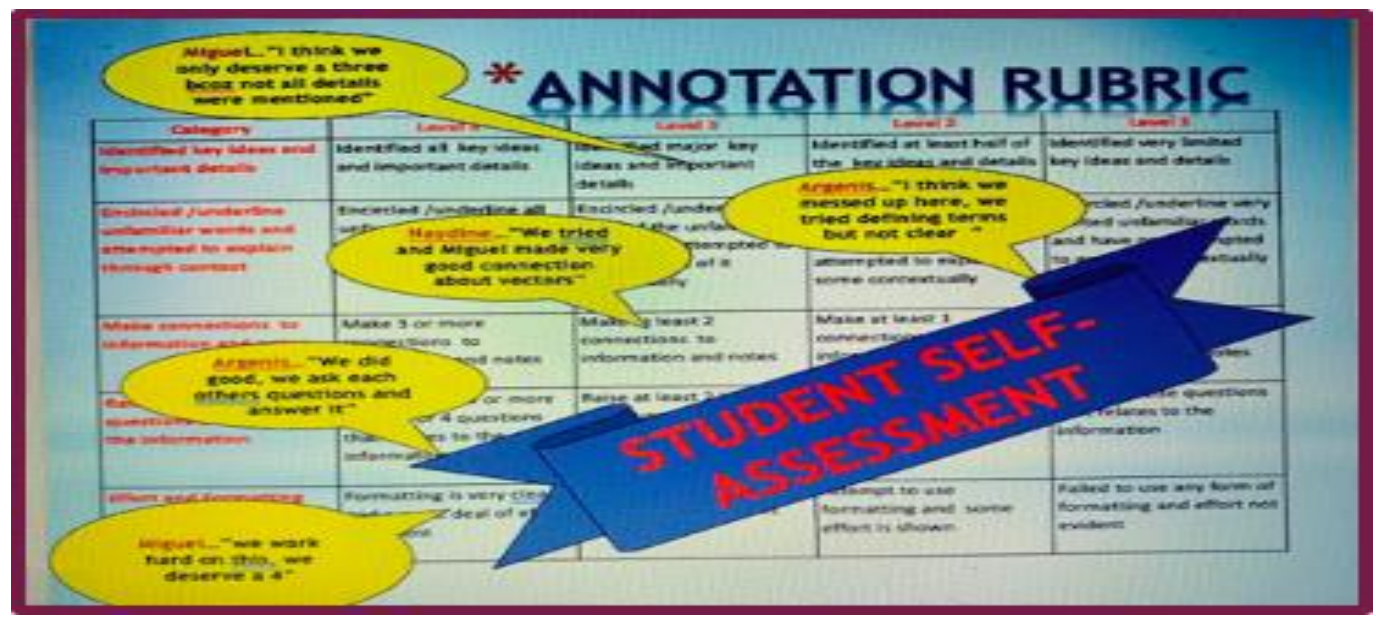

Figure 6. Student Self Reflection's Rating

During the introduction of the task, students were asked to assess their own work based on the rubric above. Students used the rubric to determine their mastery level, as illustrated in the sample students' self-assessment. They were extremely articulate about the level of work they performed as a group.

\section{Implications}

Three key findings were revealed in the case study. To begin with, identifying a student's learning style and interest can help teachers design instruction that motivates students to become involved in their learning. With the majority of students being audiovisual learners, the need to model the task physically and orally helped them dive into the task more independently. As a result, one of the key findings of this case study was that students who use written directives and rubrics rarely seek teacher assistance. Instructional goals and expectations were more likely to be met by students who receive both oral and written directives. Zimmerman (1998) supported these findings by stating that in order to be self-regulatory students must learn self-management skills. In order to enhance selfmanagement skills, you need to know what and how they can learn best (learning style), and how they can learn what they want to learn (using tracking tools).

Students need self-management skills to be able to be self-regulated and autonomous learners, and teachers play a significant role in providing students with these skills. Classroom routines and culture fostered the development of this skill. This therefore suggests the vital role that teachers play in making sure that these skills are facilitated. This is one significant finding in this action research. For example, during the study, two science teachers used the same classroom tools/ resources, yet, the difference in the quality of the student's work output was significantly different. This was due to the fact that facilitation and modeling of skills strategies were not the same. The Earth Science work sample on annotation task activity shows minimal understanding and interaction among group members compared to the Physics class work samples which was attributed to the teachers' familiarity and comfort level with the task at hand.

\subsection{Recommendations}

To assist the school in planning further professional development for teachers and staff, it is recommended that the results of this study were shared with administrators and the whole school community. According to this action research study, further training was needed for teachers on facilitation skills, as well as training on designing and using a coherent rubric and using self-assessment tools. Additionally, the use of written directions to support oral instruction should be encouraged across content areas since students become responsible for their own learning and eventually self-regulated and self-directed as a result. These instructional tools and resources should be introduced immediately and support on the use of these tools will be gradually withdrawn as the weeks progress to foster independence among each learner. 
Gitgano, R. L., Cuyacot, E. P., Cuyacot, M. T., \& Sol Cruz, F. L.

\subsection{Conclusion}

The findings from this study led to the conclusion that providing students the opportunity to develop a routine to become independent learning with the aid of written instruction and become reflective thinkers with the constant use of tracking tools and assessment criteria facilitated student-centered learning. For learners to achieve autonomy, they have to follow certain paths, which is tantamount to claiming there will be a teacher who will show them the way (Thanasoulas, 2000). Thus, the teacher class routine which included using written instruction regularly, rubric, checklist and self-assessment tools in their instructional practice is indeed showing them the way to being an autonomous learner.

\section{References}

Constructivist learning theory. Exploratorium. (2019, December 14). Retrieved February 24, 2022, from https://www.exploratorium.edu/education/ifi/constructivist-learning

Garcia, L.C. (2015). Environmental Science Issues for Higher-Order Thinking Skills (HOTS) Development: A Case Study in the Philippines. In G. Sarojini \& E. Daniel (Eds.), Biology education and research in a changing planet. Springer. https://doi.org/10.1007/978-981-287-524-2_5

Holec, H. (2001). Autonomy in foreign language learning. Oxford: Pergamon.

Little, D. (1991). Learner autonomy: definitions, issues and problems. Dublin: Authentic.

Masouleh, N. S., \& Jooneghani, R. B. (2012). Autonomous learning: A teacher-less learning! Procedia-Social and Behavioral Sciences, 55, 835-842.

Omaggio, A. (1978). Successful language learners: What do we know about them? ERIC / CLL News Bulletin, May, 2-3.

Thanasoulas, D. (2000). What is learner autonomy and how can it be fostered? The Internet TESL Journal, 4(11).

York, B. (2014). Know the child: The Importance of Teacher Knowledge of Individual Students' Skills (KISS).

Zimmerman, B. J. (1998). Developing self-fulfilling cycles of academic regulation: An analysis of exemplary instructional models. In D. H. Schunk. \& B. J. Zimmerman. (Eds.), Self-regulated learning: from teaching to self-reflective practice (pp.1-19). New York: Guilford Press. 